\title{
Capsule Commentary on Wilson et al., The Prevalence of Harmful and Hazardous Alcohol Consumption in U.S. Older Adults
}

\author{
Jeffrey L. Jackson, MD, MPH \\ Division of General Internal Medicine, Zablocki VA Medical Center, Milwaukee, WI, USA.
}

J Gen Intern Med 29(2):357

DOI: $10.1007 / \mathrm{s} 11606-013-2611-1$

(c) Society of General Internal Medicine 2013

\begin{abstract}
A lcohol plays an important role in US Society; for many, social functions such as a trip to the ballgame or an evening out would not be complete without a beer or a glass of wine. The perils of alcohol are well known; it's the leading cause of traffic fatalities in the United States and other health and social consequences of excess alcohol consumption are common. Largely in response to the social consequences of excess drinking, temperance societies have existed worldwide since the 1800s and were able to successfully ban alcohol for several years in many countries including Canada (1901-1924), Iceland (1915-1935), Finland (1919-1932), Norway (1916-1927) and the United States (1919-1933).

Wilson and colleagues found that less than half of older Americans drank at all, declining to less than one-third by age $80 .{ }^{1}$ Based on the amount consumed, they found that $15 \%$ of older drinkers exceeded recommended limits, but when other health characteristics were taken into account, drinking was potentially harmful in over one-third of those who drank. Wilson's findings are not new; they are similar to results reported in previous studies that included both the amount and the subject's health characteristics in judging the healthiness of drinking. ${ }^{2}$ This study serves to remind providers that it's not just the amount consumed that needs to be considered; even modest consumption may be harmful in patients with some health conditions. Unfortunately, most
\end{abstract}

current alcohol screens rely heavily on classifying drinking based on the amount consumed, ${ }^{3}$ and don't take into consideration comorbidities such as depression or chronic hepatitis. Unfortunately, problems in primary care providers' communication with patients about drinking have been well documented. ${ }^{4,5}$ Screening and intervention for alcohol needs to be contextualized, taking into account more than just the amount consumed, and primary care providers need better training and tools to intervene in their older adults who could be engaging in harmful drinking.

Corresponding Author: Jeffrey L. Jackson, MD, MPH; Division of General Internal Medicine, Zablocki VA Medical Center, Milwaukee, WI 53295, USA (e-mail: jjackson@mcw.edu).

\section{REFERENCES}

1. Wilson SR, Knowles SB, Huang Q, Fink A. The prevalence of harmful and hazardous alcohol consumption in U.S. older adults; Data from the 2005-2008 National Health and Nutrition Examination Survey (NHANES). $J$ Gen Intern Med, doi:10.1007/s11606-013-2577-z.

2. Kirchner JE, Zubritsky C, Cody $\mathbf{M}$ et al. Alcohol consumption among older adults in primary care. J Gen Intern Med 2007;22:92-7.

3. Bradley KA, Kivlahan DR, Williams EC. Brief approaches to alcohol screening: practical alternatives for primary care. $J$ Gen Intern Med 2009;24:881-3.

4. McCormick KA, Cochran NE, Back AL, Merrill JO, Williams EC, Bradley KA. How primary care providers talk to patients about alcohol: a qualitative study. J Gen Intern Med 2006;21:966-72.

5. Makoul G, Dhurandhar A, Goel MS, Scholtens D, Rubin AS. Communication about behavioral health risks: a study of videotaped encounters in 2 internal medicine practices. $J$ Gen Intern Med 2006;21:698-703. 